\title{
Study of alkyl chain propagation by electron beam dissociation of methyl groups on $\mathrm{Cu}\left(\begin{array}{lll}1 & 1 & 0\end{array}\right)$
}

\author{
Ping Chuang ${ }^{\text {a }}$, Y.L. Chan ${ }^{\text {b }}$, Shu-Hua Chien ${ }^{\text {a }}$, Ruth Klauser ${ }^{c}$, T.J. Chuang ${ }^{\text {b,d,* }}$ \\ a Department of Chemistry, National Taiwan University, Taipei 106, Taiwan, ROC \\ ${ }^{\mathrm{b}}$ Center for Condensed Matter Sciences, National Taiwan University, 1 Roosevelt Road, Section 4, Taipei 106, Taiwan, ROC \\ ${ }^{\mathrm{c}}$ Synchrotron Radiation Research Center, Hsinchu 300, Taiwan, ROC \\ ${ }^{\mathrm{d}}$ Institute of Atomic and Molecular Sciences, Academia Sinica, Taipei 106, Taiwan, ROC
}

\begin{abstract}
Electron irradiation on adsorbed methyl groups on $\mathrm{Cu}(110)$ at $90 \mathrm{~K}$ to produce coadsorbed methylene groups is observed by HREELS. The cross-sections for $\mathrm{CH}_{2}$ (ads) production and $\mathrm{CH}_{3}$ (ads) desorption are determined at $15 \mathrm{eV}$ e-beam energy. In TPD measurements, $\mathrm{CH}_{2}$ (ads) groups mainly react with $\mathrm{CH}_{3}$ (ads) to generate gaseous ethylene, propylene, and butene with desorption peaks centered all at $310 \mathrm{~K}$ independent of the $\mathrm{CH}_{2}$ (ads) surface concentration. The product ratio of $\mathrm{C}_{3} \mathrm{H}_{6} / \mathrm{C}_{2} \mathrm{H}_{4}$ is linearly proportional to the ratio of $\mathrm{CH}_{2}(\mathrm{ads}) / \mathrm{CH}_{3}(\mathrm{ads})$. The results suggest that aggregation of the adsorbates and close proximity of the reactants are critical for the chain propagation reaction. (C) 2002 Published by Elsevier Science B.V.
\end{abstract}

\section{Introduction}

The surface chemistry of hydrocarbons on transition metal surfaces has been widely studied to mimic the important aspects of heterogeneous catalysis [1-3]. In a number of prior studies, methylene $\left(\mathrm{CH}_{2}\right)$ is suggested to be the key species responsible for the propagation of long chain hydrocarbons from $\mathrm{C}_{1}$ methyl radicals or methane molecules [4-10]. So far, however, direct evidence to show the participation of $\mathrm{CH}_{2}$ on a metal surface to form $\mathrm{C}_{3}$ or higher mass hydrocarbons remains elusive, particularly under the ultrahigh vacuum (UHV) condition. The notable examples

\footnotetext{
${ }^{*}$ Corresponding author. Fax: +886-2-2365-5404.

E-mail address: chuangtj@ccms.ntu.edu.tw (T.J. Chuang).
}

inferring methylene insertion in the production of $\mathrm{C}_{2+}$ alkenes include recent works of $\mathrm{CH}_{3}$ (ads) chemisorbed on $\mathrm{Cu}$ [4-6] and oxygen-modified $\mathrm{Mo}$ surfaces $[9,10]$. In some cases, $\mathrm{CH}_{2} \mathrm{I}_{2}$ decomposition was used to generate methylene radicals as a reagent $[5,6]$. Yet, chemisorbed $\mathrm{CH}_{2}$ (ads) on the surface has never been clearly determined in such studies. Furthermore, the reaction kinetics of $\mathrm{CH}_{2}$ (ads) with $\mathrm{CH}_{3}$ (ads) has rarely been addressed, in particular the effects of their surface concentrations and spatial distributions. The importance to consider the spatial distribution of the reacting particles rather than the averaging surface concentration was well demonstrated by Wintterlin et al. [11] in the CO oxidation reaction. In that study, the investigators took the spatial distribution of oxygen and $\mathrm{CO}(\mathrm{ads})$ into account to revise the reaction rate law. Here we report the first 
spectroscopic evidence of methylene participation in the formation of $\mathrm{C}_{2} \mathrm{H}_{4}, \mathrm{C}_{3} \mathrm{H}_{6}$ and $\mathrm{C}_{4} \mathrm{H}_{8}$ molecules thermally desorbed from $\mathrm{Cu}(110)$ with coadsorbed $\mathrm{CH}_{2}$ and $\mathrm{CH}_{3}$ radicals and the reaction kinetics. The ratio of $\mathrm{C}_{3} \mathrm{H}_{6} / \mathrm{C}_{2} \mathrm{H}_{4}$ products is found to increase linearly with surface concentration ratio of $\mathrm{CH}_{2}$ (ads) $/ \mathrm{CH}_{3}$ (ads), rather than the average surface concentration of $\mathrm{CH}_{2}$ (ads). This observation is consistent with the methylene insertion mechanism and suggests a reaction kinetics dominated by the site-effect of chemisorption.

\section{Experimental}

$\mathrm{CH}_{3}$ radical was generated in the gas phase by pyrolysis of azomethane, and directed by a quartz nozzle source onto the $\mathrm{Cu}\left(\begin{array}{lll}1 & 1 & 0)\end{array}\right)$ surface $[9,10,12$ 14]. $\mathrm{CH}_{2}$ radical was produced as a coadsorbate by electron beam induced dissociation of chemisorbed $\mathrm{CH}_{3}$ (ads). e-Beam is known to be effective in cracking surface hydrocarbons [15-17]. The experiments were carried out in a UHV system equipped with HREELS, XPS, AES, TPD and LEED as described previously [14]. The design of the nozzle source for $\mathrm{CH}_{3}$ and its operation as well as the $\mathrm{Cu}$ surface cleaning procedures were presented in details in our prior work. The decomposition of $\mathrm{CH}_{3}$ (ads) to yield $\mathrm{CH}_{2}$ (ads) was done with a defocused low-energy electron beam provided by the LEED optics. The surface hydrocarbons were analyzed by XPS and HREELS, while the thermal reaction products were determined by TPD with a quadrupole mass spectrometer (QMS, UTI-100C).

\section{Results and discussion}

When the clean $\mathrm{Cu}(110)$ surface at $300 \mathrm{~K}$ is exposed to the $\mathrm{CH}_{3}$ source with $\mathrm{CH}_{3} \mathrm{~N}_{2} \mathrm{CH}_{3}$ as the feed gas and the quartz nozzle operated at $1100 \mathrm{~K}$, $\mathrm{CH}_{3}$ (ads) chemisorption is clearly evident by XPS and HREELS. At low exposures, some adsorbed $\mathrm{NCH}_{3}$ species is also detected due to the decomposition of the parent azomethane molecules impinging along with $\mathrm{CH}_{3}$ radicals on the surface [18]. Such N-containing species is, however, com- pletely replaced by the incoming $\mathrm{CH}_{3}$ when the gaseous exposure exceeds $1 \mathrm{~L}$ in our arrangement. Fig. 1a shows the HREELS spectrum of $\mathrm{CH}_{3}(\mathrm{ads})$ at 1 monolayer (1 ML) coverage with characteristic vibrational frequencies at $403 \mathrm{~cm}^{-1}\left(v_{\mathrm{M}-\mathrm{C}}\right)$, $1153 \mathrm{~cm}^{-1}\left(\delta_{\mathrm{s}}\right), 1427 \mathrm{~cm}^{-1}\left(\delta_{\mathrm{as}}\right), 2806 \mathrm{~cm}^{-1}\left(2 \delta_{\mathrm{s}}\right.$ Fermi resonance), $2900 \mathrm{~cm}^{-1}\left(v_{\mathrm{s}}\right)$ and 2960 $\mathrm{cm}^{-1}\left(v_{\mathrm{as}}\right)$. XPS spectra exhibit a major $\mathrm{C}(1 \mathrm{~s})$ peak at $283.4 \mathrm{eV}$ with a shoulder towards higher binding energy (near $285 \mathrm{eV}$ ), indicating the presence of a small amount of $\mathrm{CH}_{x}(\mathrm{ads})(x \leqslant 2)$ [14]. In fact, the HREELS spectra also contain some weak

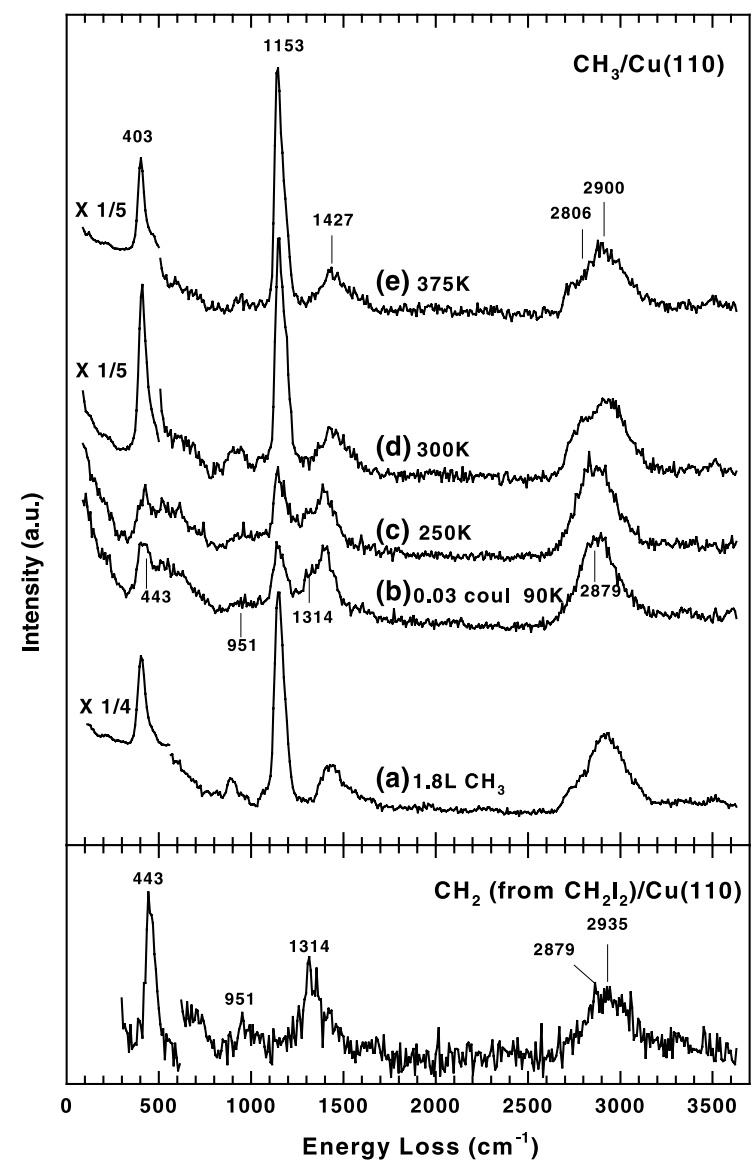

Fig. 1. HREELS spectra of: (a) $1.8 \mathrm{~L} \mathrm{CH}_{3} / \mathrm{Cu}(110)$ at $300 \mathrm{~K}$, i.e. $1 \mathrm{ML}$ coverage; (b) sample (a) cooled to $90 \mathrm{~K}$ and exposed to $68 \mathrm{eV}, 0.03 \mathrm{C}$ electrons, and then annealed to various temperatures; (c) $250 \mathrm{~K}$; (d) $300 \mathrm{~K}$; (e) $375 \mathrm{~K}$. The reference spectrum at bottom is from a submonolayer of $\mathrm{CH}_{2} \mathrm{I}_{2}$ adsorption on $\mathrm{Cu}(110)$ at $100 \mathrm{~K}$ and then annealed to $230 \mathrm{~K}$ to form $\mathrm{CH}_{2}$ (ads) species. 
signals that can be attributed to $\mathrm{CH}_{2}$ (ads). At 300 $\mathrm{K}$, the saturation surface coverage does not exceed $1 \mathrm{ML}$ when the exposure is above $1 \mathrm{~L}$, as determined by $\mathrm{C}(1 \mathrm{~s})$ and $\mathrm{Cu}(2 \mathrm{p})$ XPS signal intensities and by TPD spectra. The sample is then cooled to $90 \mathrm{~K}$ and the HREELS spectrum remains unchanged. It is subsequently irradiated by a uniform e-beam operated at $68 \mathrm{eV}$ on the entire sample with a total charge of $0.03 \mathrm{C}$ (Coulomb). After the irradiation, HREELS spectrum reveals that $\mathrm{CH}_{3}$ (ads) vibrational peaks decrease in intensity, while new peaks appear near $443 \mathrm{~cm}^{-1}\left(v_{\mathrm{M}}-\mathrm{CH}_{2}\right)$, $951 \mathrm{~cm}^{-1}\left(\rho-\mathrm{CH}_{2}\right), \quad 1314 \mathrm{~cm}^{-1}\left(\delta-\mathrm{CH}_{2}\right), \quad 2879$ $\mathrm{cm}^{-1}\left(v_{\mathrm{s}}-\mathrm{CH}_{2}\right)$ and $2935 \mathrm{~cm}^{-1}\left(v_{\mathrm{as}}-\mathrm{CH}_{2}\right)$ [14], as displayed in Fig. 1(b). These peaks clearly show the formation of $\mathrm{CH}_{2}$ (ads) from $\mathrm{CH}_{3}$ (ads). There is no significant amount of $\mathrm{CH}(\mathrm{ads})$ product which should exhibit its characteristic $\delta_{\mathrm{CH}}$ vibration near $780 \mathrm{~cm}^{-1}$. No graphitic carbon is produced by ebeam either, since the residual carbon after TPD is very small. The bottom spectrum in Fig. 1 is a reference spectrum for $\mathrm{CH}_{2}$ (ads) obtained by adsorbing a submonolayer of $\mathrm{CH}_{2} \mathrm{I}_{2}$ on $\mathrm{Cu}\left(\begin{array}{lll}1 & 1 & 0\end{array}\right)$ at $90 \mathrm{~K}$ and then annealing at $230 \mathrm{~K}$ to decompose the molecule into $\mathrm{CH}_{2}$ radicals and I atoms $[5,6]$. Clearly, the characteristic vibrational features for $\mathrm{CH}_{2}$ (ads) are very similar in both cases. In addition to the chemical decomposition, the e-beam causes some molecular desorption by electronic excitation. The effect can be detected as well by the change of $\mathrm{C}(1 \mathrm{~s})$ spectrum. As the e-beam dosage increases, the intensity ratio of $\mathrm{CH}_{2}(\mathrm{ads}) /$ $\mathrm{CH}_{3}$ (ads) also increases, but the total surface concentration of $\mathrm{CH}_{2}+\mathrm{CH}_{3}$ decreases. In a previous study of trimethyl indium on $\operatorname{GaAs}\left(\begin{array}{lll}1 & 0 & 0\end{array}\right)$ irradiated with an e-beam, the formation of a surface $\mathrm{CH}_{2}$ species was reported based on the characteristic $\delta\left(\mathrm{CH}_{2}\right)$ deformation mode at $1340 \mathrm{~cm}^{-1}$ [19]. In the e-beam study of $\left(\mathrm{CH}_{3}\right)_{3} \mathrm{Al}$ adsorbed on GaAs and InSb, the same $\delta\left(\mathrm{CH}_{2}\right)$ vibrational feature was also observed at $1340 \mathrm{~cm}^{-1}$ [20]. Therefore, we feel confident in the vibrational assignments of $\mathrm{CH}_{2}$ (ads) and $\mathrm{CH}_{3}$ (ads). The net effects of e-beam irradiation on chemisorbed $\mathrm{CH}_{3} / \mathrm{Cu}(110)$ are clearly the partial conversion of $\mathrm{CH}_{3}$ (ads) into $\mathrm{CH}_{2}$ (ads) and the desorption of hydrocarbon radicals. These e-beam induced effects are very similar in the electron energy range of 5-70 eV investigated in the present study.

Figs. 1c, d and e depict the HREELS spectra when the temperature of the e-beam irradiated sample is raised from 90 to 250,300 and $375 \mathrm{~K}$, respectively. Obviously, $\mathrm{CH}_{2}$ (ads) signals decrease drastically above $350 \mathrm{~K}$, but $\mathrm{CH}_{3}$ (ads) intensities remain relatively strong even at $375 \mathrm{~K}$. Fig. 2a illustrates the typical TPD spectra of $\mathrm{CH}_{3}$ exposed
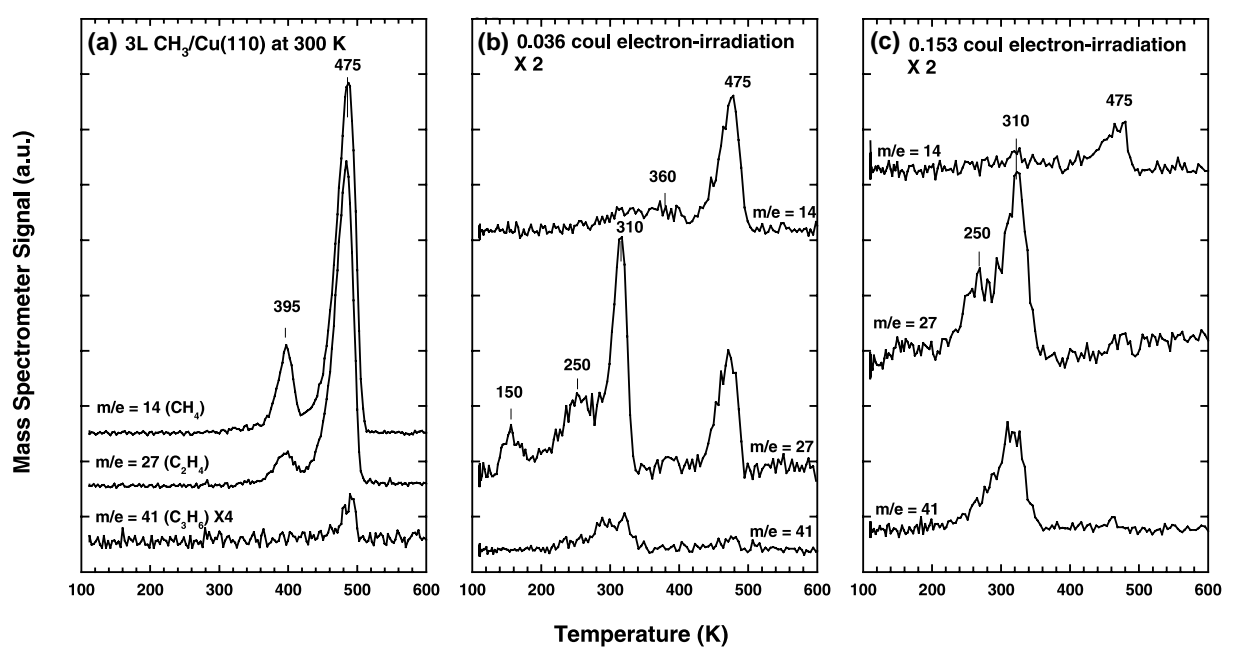

Fig. 2. TPD spectra monitoring $m / e=14\left(\mathrm{CH}_{4}\right), 27\left(\mathrm{C}_{2} \mathrm{H}_{4}\right)$, and $41\left(\mathrm{C}_{3} \mathrm{H}_{6}\right)$ after exposing $3 \mathrm{~L} \mathrm{CH}_{3}$ on $\mathrm{Cu}(110)$ at $300 \mathrm{~K}$, resulted in $1 \mathrm{ML}$ coverage (a), then cooled to $90 \mathrm{~K}$ for electron irradiation at $15 \mathrm{eV}$ energy of $0.036 \mathrm{C}$ (b) and $0.153 \mathrm{C}$ (c), respectively. 
sample with $1 \mathrm{ML}$ coverage at $300 \mathrm{~K}$ and then cooled to $90 \mathrm{~K}$ for TPD at a heating rate of $3 \mathrm{~K} / \mathrm{s}$ to $700 \mathrm{~K}$, without e-beam irradiation. The primary gaseous products as detected by the QMS are $\mathrm{CH}_{4}, \mathrm{C}_{2} \mathrm{H}_{4}, \mathrm{C}_{2} \mathrm{H}_{6}$ and $\mathrm{C}_{3} \mathrm{H}_{6}$. This is different from the prior report on $\mathrm{CH}_{3} \mathrm{I} / \mathrm{Cu}(110)$ with $\mathrm{C}_{2}$ hydrocarbons being the highest mass species evolved from the system [5]. The TPD spectra exhibit a major peak at $475 \mathrm{~K}$ for $\mathrm{CH}_{4}, \mathrm{C}_{2} \mathrm{H}_{4}$ and $\mathrm{C}_{3} \mathrm{H}_{6}$, and a minor one at $395 \mathrm{~K}$. For $\mathrm{C}_{2} \mathrm{H}_{6}$, the signal is relatively weak with a desorption peak around $470 \mathrm{~K}$. The molecular entities of these products are determined by measuring the relative signal intensities at various masses, and comparing those with the cracking patterns of our QMS. For instance, mass signals at 14,15 and 16 amu are used to identify $\mathrm{CH}_{4}, 26,27$ and 28 amu for $\mathrm{C}_{2} \mathrm{H}_{4}$, 29 and $30 \mathrm{amu}$ for $\mathrm{C}_{2} \mathrm{H}_{6}$, and 39,41 and $42 \mathrm{amu}$ for $\mathrm{C}_{3} \mathrm{H}_{6}$. The observed $\mathrm{C}_{2} \mathrm{H}_{6}$ is apparently due to the coupling of two $\mathrm{CH}_{3}$ (ads) radicals. The proximity in production and desorption temperatures for $\mathrm{CH}_{4}, \mathrm{C}_{2} \mathrm{H}_{4}$ and $\mathrm{C}_{3} \mathrm{H}_{6}$ implies similar reaction mechanism for these species. The TPD signals at 395 and $475 \mathrm{~K}$ may be due to two kinds of $\mathrm{CH}_{3}$ (ads) chemisorption sites on the corrugated surface, namely the minor and the major binding sites. In prior studies on $\mathrm{Cu}$ surfaces by Bent's group [3-6], $\mathrm{CH}_{3}$ (ads) decomposition at elevated temperatures into $\mathrm{CH}_{2}$ (ads) and $\mathrm{H}(\mathrm{ads})$ by $\alpha$ elimination was proposed to be the rate-determining step in the formation of $\mathrm{CH}_{4}$ and $\mathrm{C}_{2} \mathrm{H}_{4}$. In the suggested scheme, $\mathrm{CH}_{4}$ was originated from $\mathrm{CH}_{3}+\mathrm{H}$ reaction, while $\mathrm{C}_{2} \mathrm{H}_{4}$ was generated from $\mathrm{CH}_{3}+\mathrm{CH}_{2} \rightarrow \mathrm{C}_{2} \mathrm{H}_{5} \rightarrow \mathrm{C}_{2} \mathrm{H}_{4}(\mathrm{~g}) \uparrow+\mathrm{H}$ with $\mathrm{C}_{2} \mathrm{H}_{5}$ as an intermediate species. We find that this scheme is generally operative in our system.

Figs. $2 \mathrm{~b}$ and $\mathrm{c}$ depict the TPD spectra after 1 $\mathrm{ML}$ of $\mathrm{CH}_{3}$ (ads) at $90 \mathrm{~K}$ is irradiated by e-beam at $15 \mathrm{eV}$ energy with 0.036 and $0.153 \mathrm{C}$ of electrons, respectively. Apart from $\mathrm{CH}_{4}, \mathrm{C}_{2} \mathrm{H}_{4}$ and $\mathrm{C}_{3} \mathrm{H}_{6}$, we also detect some $\mathrm{C}_{4} \mathrm{H}_{8}$ signal. The desorption temperature of molecular $\mathrm{C}_{2} \mathrm{H}_{4}$ on $\mathrm{Cu}(110)$ has been reported at $190 \mathrm{~K}$ with heating rate of $2.5 \mathrm{~K} / \mathrm{s}$ [21]. A prior study on $\mathrm{CH}_{2} \mathrm{I}_{2} / \mathrm{Cu}(110)$ indicated that the combination of $\mathrm{CH}_{2}$ to form $\mathrm{C}_{2} \mathrm{H}_{4}$ was at 290-300 K [5]. It was also suggested that $\mathrm{CH}_{2}$ could react with $\mathrm{CH}_{3}$ and be desorbed as $\mathrm{C}_{2} \mathrm{H}_{4}$ at $345 \mathrm{~K}$. Therefore, from our own measurements and these prior studies, we can assign the small $\mathrm{C}_{2} \mathrm{H}_{4}$ signal at $150 \mathrm{~K}$ to ethylene, which is generated by $\mathrm{CH}_{2}$ coupling but trapped on the surface at $90 \mathrm{~K}$. Above $200 \mathrm{~K}$, the main reaction channels for $\mathrm{CH}_{2}$ (ads) are bimolecular reaction to form $\mathrm{C}_{2} \mathrm{H}_{4}$ at $250 \mathrm{~K}$ and $\mathrm{CH}_{2}+\mathrm{CH}_{3} \rightarrow \mathrm{C}_{2} \mathrm{H}_{5} \rightarrow$ $\mathrm{C}_{2} \mathrm{H}_{4}(\mathrm{~g}) \uparrow+\mathrm{H}$ at $310 \mathrm{~K}$. For the e-beam irradiated sample, the production and desorption signals for $\mathrm{C}_{3} \mathrm{H}_{6}$ and $\mathrm{C}_{4} \mathrm{H}_{8}$ occur mainly also at $310 \mathrm{~K}$. It is suggested that the intermediate $\mathrm{C}_{2} \mathrm{H}_{5}(\mathrm{ads})$ species react further with $\mathrm{CH}_{2}$ (ads) via $\mathrm{C}_{2} \mathrm{H}_{5}+\mathrm{CH}_{2} \rightarrow$ $\mathrm{C}_{3} \mathrm{H}_{7} \rightarrow \mathrm{C}_{3} \mathrm{H}_{6}(\mathrm{~g}) \uparrow+\mathrm{H}$ and $\mathrm{C}_{3} \mathrm{H}_{7}+\mathrm{CH}_{2} \rightarrow$ $\mathrm{C}_{4} \mathrm{H}_{9} \rightarrow \mathrm{C}_{4} \mathrm{H}_{8}(\mathrm{~g}) \uparrow+\mathrm{H}$ in the chain propagation processes. These products all desorb at around 310 $\mathrm{K}$, independent of $\mathrm{CH}_{2}(\mathrm{ads})$ concentration and exhibiting the first-order reaction kinetics. Fig. 3 illustrates in more details the TPD spectra of $\mathrm{C}_{2} \mathrm{H}_{4}$ and $\mathrm{C}_{3} \mathrm{H}_{6}$ with various electron dosages as indicated. The peaks at $310 \mathrm{~K}$ clearly show that the amount of $\mathrm{C}_{3} \mathrm{H}_{6}$ production increases at a faster rate than that of $\mathrm{C}_{2} \mathrm{H}_{4}$ as a function of e-beam dosage. In both Figs. 2 and 3, the additional signals for $\mathrm{CH}_{4}, \mathrm{C}_{2} \mathrm{H}_{4}$ and $\mathrm{C}_{3} \mathrm{H}_{6}$ at 395 and $475 \mathrm{~K}$ are due to $\mathrm{CH}_{3}$ (ads) reactions as discussed above for the non-irradiated sample. The weak $\mathrm{CH}_{4}$ peak at $360 \mathrm{~K}$ is attributed to the desorption of $\mathrm{H}(\mathrm{ads})$ via the reaction with $\mathrm{CH}_{3}$. The temperature depen-

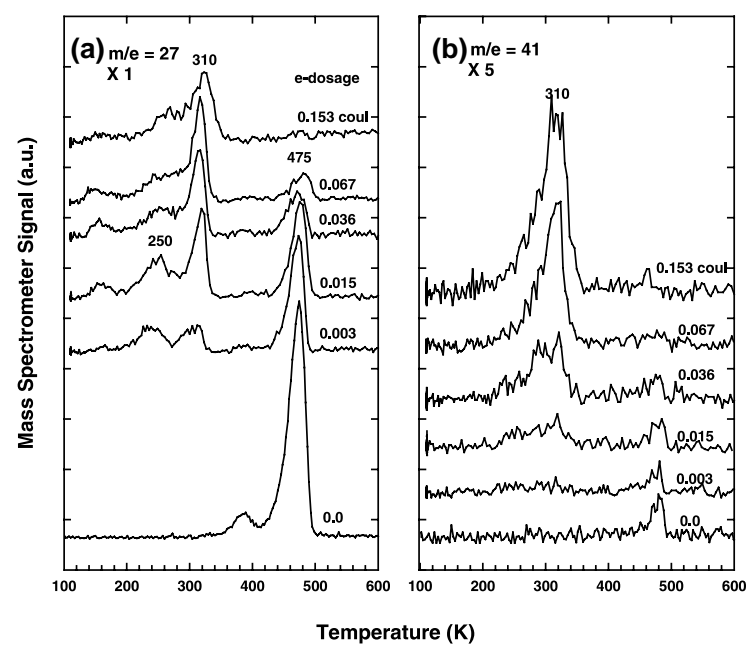

Fig. 3. TPD spectra monitoring $m / e=27\left(\mathrm{C}_{2} \mathrm{H}_{4}\right)$, and 41 $\left(\mathrm{C}_{3} \mathrm{H}_{6}\right)$ with various electron dosages at $15 \mathrm{eV}$ energy as indicated. 
dence of the HREELS spectra (Fig. 1) is closely correlated with the TPD spectra to support the interpretation.

According to the reaction scheme as discussed above, the surface concentrations of $\mathrm{CH}_{2}$ (ads) and $\mathrm{CH}_{3}$ (ads) after electron irradiation can be calculated from the TPD data. Clearly the formation of every $\mathrm{CH}_{4}, \mathrm{C}_{2} \mathrm{H}_{4}, \mathrm{C}_{3} \mathrm{H}_{6}$ and $\mathrm{C}_{4} \mathrm{H}_{8}$ molecule consumes one $\mathrm{CH}_{3}$ (ads). Therefore, by calculating the desorption amount of these four species at 310 , 395 and $475 \mathrm{~K}$, we can determine the surface concentration of $\mathrm{CH}_{3}(\mathrm{ads})$. Likewise, the surface concentration of $\mathrm{CH}_{2}$ (ads) can be obtained in the same manner with the addition of extra $\mathrm{C}_{2} \mathrm{H}_{4}$ peak at $250 \mathrm{~K}$. The desorption amount of each species is calculated by integrating the peak area of TPD spectra corrected with the sensitivity factors of QMS. These factors are in turn calibrated using methane, ethylene, ethane and propylene standard gases. The results of such analysis are plotted in Fig. 4 as a function of electron dosage. Repetitive measurements show that the experimental uncertainty is about $\pm 10 \%$. The total surface carbon as a function of e-beam dosage can also be directly measured from the C(1s) XPS signal. The result by XPS is practically the same as that obtained by

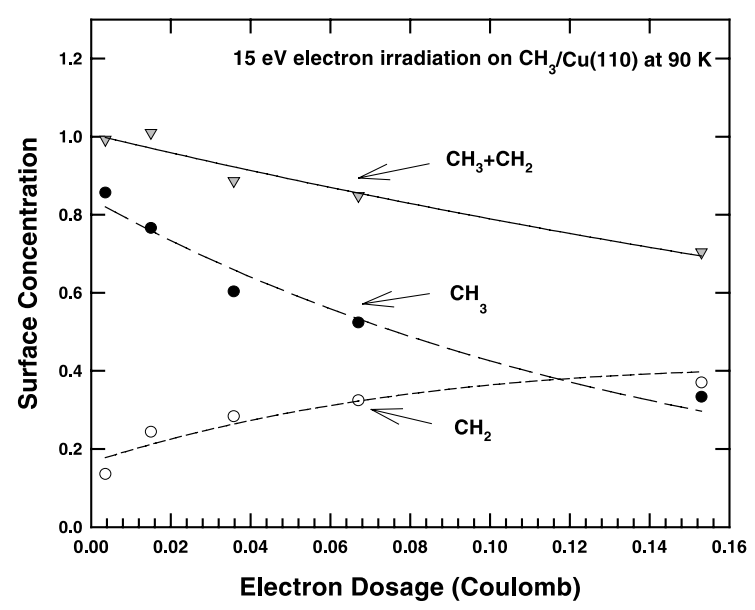

Fig. 4. Surface concentrations as a function of electron dosage on $\mathrm{CH}_{3} / \mathrm{Cu}(110)$ at $90 \mathrm{~K}$. The relative concentrations of $\mathrm{CH}_{2}$ (open circles), $\mathrm{CH}_{3}$ (solid circles) and total carbon (triangle down) are calculated from TPD data. The solid, long dash, and short dash lines are fitting results of $\left(\mathrm{CH}_{2}+\mathrm{CH}_{3}\right), \mathrm{CH}_{3}$ and $\mathrm{CH}_{2}$, respectively.
TPD. Under the e-beam, $\mathrm{CH}_{3}$ (ads) groups may be either desorbed or dissociated. The desorption and dissociation cross-sections can be obtained by fitting the decreases of both $\mathrm{CH}_{3}$ (ads) and total carbon surface concentration $(\theta)$ to the following expression:

$\theta(\gamma)=\theta_{0} \mathrm{e}^{-\sigma \gamma}$,

where $\gamma$ is the electron dosage in Coulomb, and $\sigma$ the effective cross-section. From the decrease of total surface hydrocarbon $\left(\mathrm{CH}_{2}+\mathrm{CH}_{3}\right.$, top curve in Fig. 4) as a function of $\gamma$, we determine the desorption cross-section $\left(\sigma_{\mathrm{p}}\right)$ of $\mathrm{CH}_{3}$ (ads) to be $7.7 \times 10^{-19} \mathrm{~cm}^{2}$. Likewise, the total cross-section $\left(\sigma_{\mathrm{t}}\right)$ for both $\mathrm{CH}_{3}$ desorption and dissociation to form $\mathrm{CH}_{2}$ is calculated to be $2.17 \times 10^{-18} \mathrm{~cm}^{2}$, based on the decreasing signal of $\mathrm{CH}_{3}$ (ads) as a function of $\gamma$. In the fitting, the initial surface concentrations $\left(\theta_{0}\right)$ of total carbon and $\mathrm{CH}_{3}(\mathrm{ads})$ are taken to be 1.0 and 0.85 , respectively. The dissociation cross-section $\left(\sigma_{\mathrm{d}}\right)$ is then obtained by subtracting $\sigma_{\mathrm{p}}$ from $\sigma_{\mathrm{t}}$ and found to be $1.4 \times 10^{-18} \mathrm{~cm}^{2}$. This value can be compared with the $\mathrm{CH}_{3} / \mathrm{Pt}\left(\begin{array}{lll}1 & 1 & 1\end{array}\right)$ system, in which a dissociation cross-section of $<1 \times 10^{-17} \mathrm{~cm}^{2}$ was reported with the electron energy at $50 \mathrm{eV}$ [16]. The electron energy effects on cross-sections have also been examined. It is found that in the range of $5-70 \mathrm{eV}$, the dissociation cross-section increases with electron energy, while the desorption cross-section is quite independent of that factor.

The alkyl chain reaction mechanism can be further elucidated by examining the relation of product ratios and surface composition. In the reaction scheme as mentioned above, the desorption products of $\mathrm{C}_{2} \mathrm{H}_{4}, \mathrm{C}_{3} \mathrm{H}_{6}$ and $\mathrm{C}_{4} \mathrm{H}_{8}$ at $310 \mathrm{~K}$ are generated by sequential $\mathrm{CH}_{2}$-insertion reactions. Accordingly, the production rate for ethylene should be proportional to $\left[\mathrm{CH}_{2}\right]$ surface concentration, whereas that for propylene should depend on $\left[\mathrm{CH}_{2}\right]^{2}$. Namely, the yield ratio of $\mathrm{C}_{3} \mathrm{H}_{6} / \mathrm{C}_{2} \mathrm{H}_{4}$ should be proportional to $\mathrm{CH}_{2}$ (ads) concentration. When we plot the ratio of $\mathrm{C}_{3} \mathrm{H}_{6} / \mathrm{C}_{2} \mathrm{H}_{4}$ as a function of $\mathrm{CH}_{2}$ (ads), however, it shows a non-linear (actually superlinear) dependence. This means that the conventional kinetic theory used in the gas and liquid phases, in which the reaction rate depends on the average concen- 
tration of the reactants, is not applicable in the present system. In considering the formation of $\mathrm{C}_{3} \mathrm{H}_{6}$, the lifetime of $\mathrm{C}_{2} \mathrm{H}_{5}$ (ads) intermediate species must be taken into account. Within the transient lifetime of $\mathrm{C}_{2} \mathrm{H}_{5}(\mathrm{ads})$, it can be desorbed as $\mathrm{C}_{2} \mathrm{H}_{4}$ or react further with $\mathrm{CH}_{2}$ (ads) to form $\mathrm{C}_{3} \mathrm{H}_{7}$ (ads). If $\mathrm{C}_{2} \mathrm{H}_{5}$ (ads) is surrounded by $\mathrm{CH}_{3}$ (ads), $\mathrm{C}_{2} \mathrm{H}_{4}$ desorption would be favored. On the other hand, if $\mathrm{C}_{2} \mathrm{H}_{5}$ (ads) has $\mathrm{CH}_{2}$ (ads) as its immediate neighbor, then $\mathrm{C}_{3} \mathrm{H}_{6}$ production would be enhanced. Therefore, it seems reasonable to plot the product ratio of $\mathrm{C}_{3} \mathrm{H}_{6} / \mathrm{C}_{2} \mathrm{H}_{4}$ as a function of $\mathrm{CH}_{2}$ (ads) $/ \mathrm{CH}_{3}$ (ads). This is displayed in Fig. 5, and indeed it shows a good linearity. The result indicates that a high concentration of $\mathrm{CH}_{3}(\mathrm{ads})$ can cause the transient $\mathrm{C}_{2} \mathrm{H}_{5}$ to be surrounded by $\mathrm{CH}_{3}$ (ads), and this can inhibit the further reaction of $\mathrm{C}_{2} \mathrm{H}_{5}$ with $\mathrm{CH}_{2}$ (ads). Apparently, $\mathrm{CH}_{2}$ (ads) sitting very nearby the transient species is crucial for the production of higher mass hydrocarbons. Surface diffusion of $\mathrm{CH}_{2}(\mathrm{ads})$ seems to be too slow for the chain propagation reactions.

In further studies of $\mathrm{CH}_{3}$ on $\mathrm{Cu}\left(\begin{array}{lll}1 & 1 & 1\end{array}\right)$ and $\mathrm{Cu}\left(\begin{array}{lll}1 & 1 & 0)\end{array}\right)$ by LEED, we find that $\mathrm{CH}_{3}$ (ads) groups tend to form two-dimensional (2D) islands on the metal surfaces, even at a small surface coverage $(\theta \ll 1)$. Namely, the chemisorbed radicals prefer to aggregate together rather than spread out uniformly on the $\mathrm{Cu}$ surface. Under e-beam irradia-

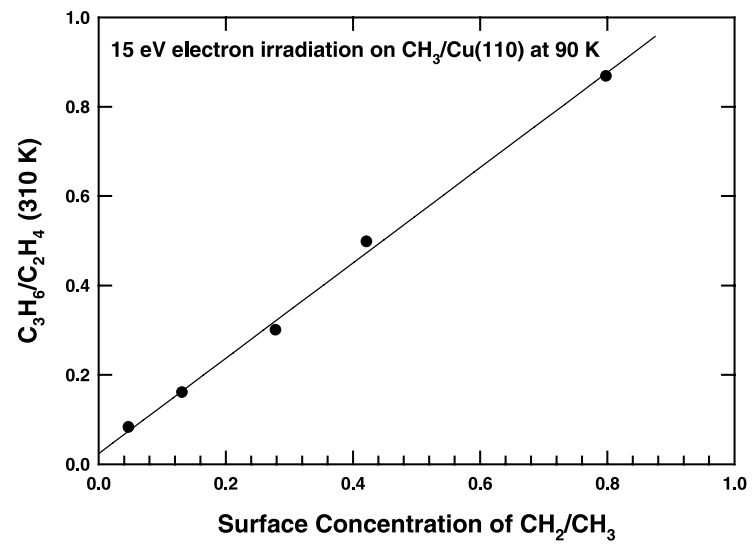

Fig. 5. The product ratio of $\mathrm{C}_{3} \mathrm{H}_{6} / \mathrm{C}_{2} \mathrm{H}_{4}$ desorbed at $310 \mathrm{~K}$ is plotted as a function of surface concentration ratio of $\mathrm{CH}_{2} / \mathrm{CH}_{3} \cdot \mathrm{CH}_{2}$ is produced by irradiation of $\mathrm{CH}_{3} / \mathrm{Cu}(110)$ at $90 \mathrm{~K}$ with $15 \mathrm{eV}$ electrons. tion, $\mathrm{CH}_{2}$ (ads) is generated from $\mathrm{CH}_{3}$ (ads) and the two species can coexist in the mixed 2D islands on $\mathrm{Cu}\left(\begin{array}{ll}1 & 10)\end{array}\right)$. In such case, the possibility of $\mathrm{CH}_{2}$ (ads) occupying the neighboring sites of a transient species can be proportional to the ratio of $\mathrm{CH}_{2}$ (ads) $/ \mathrm{CH}_{3}$ (ads). The good linearity of $\mathrm{C}_{3} \mathrm{H}_{6} / \mathrm{C}_{2} \mathrm{H}_{4}$ vs $\mathrm{CH}_{2}$ (ads) $/ \mathrm{CH}_{3}$ (ads) is consistent with such chemisorption geometry. Furthermore, the peak positions of $\mathrm{C}_{2} \mathrm{H}_{4}, \mathrm{C}_{3} \mathrm{H}_{6}$ and $\mathrm{C}_{4} \mathrm{H}_{8}$ desorption directly correlated with the chain reactions are found to be the same (near $310 \mathrm{~K}$ ), and independent of the surface concentration of $\mathrm{CH}_{2}$ (ads). This fact provides additional support that it is the nearby $\mathrm{CH}_{2}$ (ads) but not the diffused $\mathrm{CH}_{2}$ (ads) to participate in the formation of propylene and butene products.

\section{Summary}

Irradiation by low-energy electrons on chemisorbed methyl groups on $\mathrm{Cu}\left(\begin{array}{lll}1 & 1 & 0\end{array}\right)$ can induce desorption and molecular dissociation into methylene radicals. These effects are investigated and verified by XPS, TPD and HREELS surface analytical techniques. By controlling the e-beam dosage, we can vary the relative surface concentrations of coadsorbed $\mathrm{CH}_{2}(\mathrm{ads})$ and $\mathrm{CH}_{3}(\mathrm{ads})$ and study their reaction behavior. With this approach, the $\mathrm{CH}_{3}$ (ads) dissociation and desorption cross-sections are determined at $15 \mathrm{eV}$ e-beam energy to be $1.4 \times 10^{-18}$ and $7.7 \times 10^{-19} \mathrm{~cm}^{2}$, respectively. Gaseous $\mathrm{C}_{2} \mathrm{H}_{4}, \mathrm{C}_{3} \mathrm{H}_{6}$ and $\mathrm{C}_{4} \mathrm{H}_{8}$ molecules are found to evolve from the surface covered with the two radical species in TPD measurements. The peak desorption temperatures of these products are observed all around $310 \mathrm{~K}$ independent of the $\mathrm{CH}_{2}$ (ads) surface concentration. A hydrocarbon chain propagation reaction scheme involving $\mathrm{CH}_{2}$ (ads) insertion and the formation of transient alkyl intermediate species has been extended to account for the observed phenomenon. Further analysis of the $\mathrm{C}_{3} \mathrm{H}_{6} / \mathrm{C}_{2} \mathrm{H}_{4}$ product ratios as a function of electron dosage reveals that it is linearly proportional to the ratio of $\mathrm{CH}_{2}(\mathrm{ads}) /$ $\mathrm{CH}_{3}$ (ads) surface concentrations. By considering the lifetime of transient species in the chain reactions, we conclude that aggregation of the adsor- 
bates in the form of 2D islands and close proximity of the reactants are essential for the generation of high mass products.

\section{Acknowledgements}

The authors wish to thank the National Science Council and the Ministry of Education of ROC for the support of this work.

\section{References}

[1] F. Zaera, Chem. Rev. 95 (1995) 2651.

[2] G.A. Somorjai, Chem. Rev. 96 (1996) 1223.

[3] B.E. Bent, Chem. Rev. 96 (1996) 1361.

[4] J.L. Lin, B.E. Bent, J. Vac. Sci. Technol. A 10 (1992) 2202.

[5] C.M. Chiang, T.H. Wentzlaff, B.E. Bent, J. Phys. Chem. 96 (1992) 1836.

[6] J.L. Lin, C.M. Chiang, C.J. Jenks, M.X. Yang, T.H. Wentzlaff, B.E. Bent, J. Catal. 147 (1994) 250.
[7] H.J. Wu, H.K. Hsu, C.M. Chiang, J. Am. Chem. Soc. 121 (1999) 4433.

[8] R.C. Brady, R. Pettit, J. Am. Chem. Soc. 102 (1980) 6182.

[9] S.H. Kim, P.C. Stair, J. Am. Chem. Soc. 120 (1998) 8535.

[10] S.H. Kim, P.C. Stair, J. Phys. Chem. B 104 (2000) 3035.

[11] J. Wintterlin, S. Volkening, T.V.W. Janssens, T. Zambelli, G. Ertl, Science 278 (1997) 1931.

[12] X.D. Peng, R. Viswanathan, G.H.J. Smudde, P.C. Stair, Rev. Sci. Instrum. 63 (1992) 3930.

[13] Y.L. Chan, P. Chuang, T.J. Chuang, J. Vac. Sci. Technol. A 16 (1998) 1023.

[14] T.J. Chuang, Y.L. Chan, P. Chuang, R. Klauser, J. Electr. Spectr. Relat. phenom. 98\&99 (1999) 149.

[15] X.-L. Zhou, J.M. White, J. Phys. Chem. 96 (1992) 7703.

[16] D.J. Alberas-Sloan, J.M. White, Surf. Sci. 365 (1996) 212.

[17] Y.L. Tsai, B.E. Koel, Langmuir 14 (1998) 1290.

[18] P. Chuang, Y.L. Chan, C.H. Chuang, S.-H. Chien, T.J. Chuang, Appl. Surf. Sci. 169\&170 (2001) 153.

[19] A.A. Aquino, C.P.A. Mulcahy, T.S. Jones, Chem. Phys. Lett. 252 (1996) 159.

[20] C.P.A. Mulcahy, J. Eggeling, T.S. Jones, Chem. Phys. Lett. 288 (1998) 203.

[21] C.J. Jenks, A. Paul, L.A. Smoliar, B.E. Bent, J. Phys. Chem. 98 (1994) 572. 